\title{
Objective age of acquisition norms for a set of 328 words in Spanish
}

\author{
Bernardo Álvarez and Fernando Cuetos \\ University of Oviedo, Oviedo, Spain
}

\begin{abstract}
Age of acquisition is one of the most important variables in picture naming. For this reason, a large number of findings concerning age-of-acquisition data have been published in recent years in a number of different languages. In this article, objective age-of-acquisition data in Spanish for 328 pictures were collected from a pool of 760 children, half of whom were boys and the other half girls. A total of 246 pictures were selected from the Snodgrass and Vanderwart (1980) set, and 82 were new pictures. Like the results of other studies, we found that objective age of acquisition correlates less than rated age of acquisition with familiarity and frequency, which indicates that the objective measure is less contaminated by other variables than are rated estimates. A very high correlation was obtained between the norms from this study and those published in English, French, Icelandic, and Italian. These norms will be very useful to Spanish psycholinguists and clinicians. Related materials may be downloaded from the Psychonomic Society Web archive at www.psychonomic.org/archive/.
\end{abstract}

Since the pioneering work of Carroll and White (1973) on the effects of age of acquisition (AoA) in tasks of lexical access, many different studies have confirmed the relevance of this variable in predicting reaction times (RTs): Words that were learned early in life tend to be read with shorter latencies than those learned later on. The effect of AoA is especially important in the picture-naming task (see, e.g., Barry, Morrison, \& Ellis, 1997; Bonin, Boyer, Méot, Fayol, \& Droit, 2004; Cuetos, Ellis, \& Álvarez, 1999; Ellis \& Morrison, 1998; Morrison, Hirsh, Chappell, \& Ellis, 2002), but it also has an influence on lexical decision (e.g., Bonin, Chalard, Méot, \& Fayol, 2001; Brysbaert, Lange, \& Van Wijnendaele, 2000; Gerhand \& Barry, 1999; Morrison \& Ellis, 1995), word naming (e.g., Brysbaert et al., 2000; Cuetos \& Barbón, 2006; Gerhand \& Barry, 1998; Monaghan \& Ellis, 2002; Morrison \& Ellis, 1995), object decision (e.g., Holmes \& Ellis, 2006; Vitkovitch \& Tyrrell, 1995), and face-naming latencies (Moore \& Valentine, 1998). Moreover, not only does AoA influence healthy subject RTs, it has also been found to affect the accuracy of response in aphasic patients (e.g., Cuetos, Aguado, Izura, \& Ellis, 2002; Hirsh \& Ellis, 1994; Nickels \& Howard, 1995), patients with Alzheimer's disease (e.g., Cuetos, González-Nosti, \& Martínez, 2005; Forbes-McKay, Ellis, Shanks, \&Venneri, 2005; Lambon Ralph, Graham, Ellis, \& Hodges, 1998), dyslexic patients (Barry \& Gerhand, 2003), dysgraphic patients (Weekes, Davies, Parris, \& Robinson, 2003), and deaf people (Cuetos, Monsalve, Pinto, \& Rodríguez-Ferrero, 2004). The effects of this variable are also shown when physiological measurements are taken using the evoked response potential (ERP) methodology (Tainturier, Johnson, Tamminen,
\& Thierry, 2003), in which a bigger positivity is observed for those words that were acquired in an early stage of life, or with the techniques of fMRI (e.g., Fiebach, Friederici, Müller, Von Cramon, \& Hernández, 2003; Hernández \& Fiebach, 2006; Postler et al., 2004; Weekes, Chan, Kwok, Tan, \& Jin, 2004), in which the activation of different brain areas is noted for words acquired in both an early and later stage of life.

Given the importance that AoA seems to have for both psycholinguistics and clinical studies, a large number of AoA scales have been published in recent years in a number of different languages: English (see, e.g., Gilhooly \& Logie, 1980a, 1980b; Morrison, Chappell, \& Ellis, 1997), French (Alario \& Ferrand, 1999), Italian (Dell'Acqua, Lotto, \& Job, 2000), Spanish (Cuetos et al., 1999), Dutch (Ghyselinck, De Moor, \& Brysbaert, 2000), and Icelandic (Pind, Jónsdóttir, Tryggvadóttir, \& Jónsson, 2000). The most common procedure that is followed to obtain AoA variables was first set out by Gilhooly and Logie (1980a, $1980 \mathrm{~b})$, who gave lists of words to a group of adults and asked them to rate when they thought they had learned the words. In some cases (e.g., Alario \& Ferrand, 1999), this scale ranges between 1 and 5 , with 1 meaning the word had been learned before the individual had reached the age of 3 , and 5 meaning it had been learned after the individual had reached the age of 12 . In other cases (e.g., Gilhooly \& Logie, 1980a, 1980b; Morrison et al., 1997; Pind et al., 2000 ), the scale goes from 1 to 7 , each point being equivalent to 2 years in age. Finally, in some cases (e.g., Cuetos et al., 1999), the scale goes from 1 to 11 , each point being equal to one year: 1 before 2 years old, 2 between 2 and 3 years, and so on through 11 more than 11 years old. 
A potential problem with these scales is that they rely on the subjective judgment of participants. Because it is very difficult to remember at what age we learned words, our answers can be influenced by other variables, such as word frequency or familiarity. The impression of familiarity may evoke a judgment of early AoA that is, in fact, incorrect. A very tight correlation between subjective AoA and measures of familiarity or frequency has been found. Cuetos et al. (1999) reported a correlation of .58 between AoA and familiarity, and of .38 between AoA and word frequency. Barca, Burani, and Arduino (2002) reported a still greater correlation between AoA and familiarity or frequency, of .80 and .72 , respectively.

Thus, researchers have searched for other kinds of measurements that could be considered objective-for example, opinions about children's vocabulary reported by parents or teachers (see, e.g., Caselli \& Casadio, 1995; Kohnstamm, Schaerlaekens, De Vries, Akkerhuis, \& Froonincksx, 1981), observation of individual cases (Jorm, 1991), counts of oral and spontaneous productions (Piñeiro \& Manzano, 2000), or works on language (see, e.g., Yamada, Takashima, \& Yamazaki, 1998; Yamazaki, Ellis, Morrison, \& Lambon Ralph, 1997). One method that many authors have used that certainly seems objective was first reported by Morrison et al. (1997), who showed pictures of objects to children of different ages for naming: "The idea is that if a child can name a picture then it has acquired the word (and its meaning). If a majority of an age group sample can name a picture then it is likely that the word is normatively acquired at least as young as that age." Following this procedure, Morrison et al. (1997) obtained AoA values for 297 English words. Using the same method, Barbarotto, Laiacona, and Capitani (2005) obtained AoA values for 80 Italian words; Chalard, Bonin, Méot, Boyer, and Fayol (2003) obtained AoA values for 230 French words; and Pind et al. (2000) obtained AoA values for 238 Icelandic words. All these studies mainly used names corresponding to the Snodgrass and Vanderwart (1980) pictures set, since these pictures have already been standardized, and since extensive sets of normative data on other psycholinguistic variables have already been collected for them.

In Spanish, Pérez and Navalón (2005) recently published objective AoA norms for 175 Spanish words, following the same procedure as that of Morrison et al. (1997), but only 111 of their items corresponded to the pictures of Snodgrass and Vanderwart (1980). However, since the Snodgrass and Vanderwart pictures are the most widely used - as much in psycholinguistic investigations as in clinical studies - and since we also have normative data in Spanish about the familiarity, name agreement, image agreement, and visual complexity for these items (Sanfeliu \& Fernández, 1996), we think it is necessary to provide data on objective AoA not only for all of Snodgrass and Vanderwart's pictures, but also for several more items so that the psycholinguist or clinical psychologist can have as great a number of stimuli as possible to manipulate this influential variable. We report objective AoA values for Snodgrass and Vanderwart pictures (Study 1) as well as for a further set of common objects not included in that set (Study 2).

\section{STUDY 1 \\ Snodgrass and Vanderwart (1980) Pictures Set}

\section{Method}

Participants. A total of 380 schoolchildren (190 girls and 190 boys) took part in the study. These children went to infant, primary, or secondary schools in Oviedo, Spain. Their ages ranged from 2 years and 4 months to 15 years. All of them had normal or corrected-tonormal sight, all of them had a normal level of intelligence, and for each of them, the native language was Spanish. These 380 children were recruited in groups according to 19 age bands, with 20 children ( 10 boys and 10 girls) in each group. Up to the age of 8 years old, we tested children whose ages ranged within bands of 6 months of each other. At ages greater than 8 years, we tested children in groups whose ages ranged within 1-year age bands. Therefore, there were 12 age bands of 6 months each (from 28-33 to 91-96), and 7 age bands of 12 months each (from 97-108 to 168-179). Information about the 19 age bands is shown in Table 1.

Stimuli. The 260 Snodgrass and Vanderwart (1980) pictures were printed on white cards that were $10 \mathrm{~cm}$ wide by $14.5 \mathrm{~cm}$ long. Each picture was presented on a different card.

Procedure. The procedure was very similar to that used in previous studies by Morrison et al. (1997), Chalard et al. (2003), or Pérez and Navalón (2005). Each child was evaluated individually in his or her own school on the school's timetable, and only after the experimenter had established a good rapport with the participant. The task was explained to each child at the start of testing. He or she was shown the test pictures and was told "You have to tell me how you name these things." As the participant named the pictures, the experimenter noted one of the following on the answer sheet: if the child answered with the right word, if the answer was wrong, or if the child did not answer because he or she did not know the object in the card. If the child had doubts, we gave instructions to say that he or she did not remember in that moment. Or, if the name was on "the tip of the tongue," and the picture was set aside, the child was asked to go on with the test and was told that the picture would be shown later on. At the end, the item was presented again and the answer was registered as those for the previous ones.

We started by the 156-167 age band so that the youngest children only had to name a small number of stimuli, because we supposed that those pictures that could not have been named by older children could not be named by the younger children either.

Table 1

Age Bands (in Months) and Mean Age (in Months)

\begin{tabular}{cc}
\hline Age Bands & Mean Age \\
\hline $28-33$ & 30 \\
$34-39$ & 36 \\
$40-45$ & 43 \\
$46-51$ & 49 \\
$52-57$ & 54 \\
$58-63$ & 61 \\
$64-69$ & 66 \\
$70-75$ & 72 \\
$74-79$ & 76 \\
$80-85$ & 82 \\
$85-90$ & 87 \\
$91-96$ & 93 \\
$97-108$ & 102 \\
$108-119$ & 114 \\
$120-131$ & 126 \\
$132-143$ & 136 \\
$144-155$ & 150 \\
$156-167$ & 160 \\
$168-179$ & 173
\end{tabular}

Note- Each age band included a total of 20 participants (10 male and 10 female). 
When all the pictures had been shown to all the children in an age band, the right and wrong answers for each stimulus were collated. Then, the arithmetic mean of the ages of the children in the group was calculated in months, and we calculated the percentage naming agreement for each picture in each group. We considered that a name was acquired at the mean age of a group when the percentage was either equal or superior to $75 \%$ or to the percentage of name agreement in that group that was obtained in a sample of adults.

\section{Results}

When all of the data had been collected, we compiled a table with the AoA of each object, and we applied the same procedure as did Morrison et al. (1997) to 18 objects that did not reach the criterion of acquisition in the highest age group that was tested (173 months), thus considering these items to be normatively acquired at 173 months + 1 year. However, we did not follow the procedure of Morrison et al. (1997) for those stimuli that elicited name agreement at a percentage equal to or higher than $90 \%$. Morrison et al. (1997) reduced the object's AoA by some months according to the percentage agreement. We could not do this, since we did not have similar documents in Spanish.

\section{STUDY 2 173 New Pictures}

A total of 173 black and white line drawings of a new set of objects were made for this study. Their stroke and detail complexity was similar to that of the pictures used by Snodgrass and Vanderwart (1980). Some of these new pictures were taken from encyclopedias, tests, dictionaries, and computerized image batteries. All of the pictures were retouched so that they had the same format as that used by Snodgrass and Vanderwart (the pictures can be downloaded from www.psychonomic.org/archive/). These 173 pictures were first shown to a group of adults (teachers and students from the education faculty) in a naming test. This was done to discover adult name agreement. Only those pictures that reached no less than $75 \%$ of name agreement were selected for further testing. There were 51 pictures that did not reach this percentage and were eliminated. Our sample was reduced to 122 pictures. Of these 122 pictures, 37 depicted objects that were also tested by Snodgrass and Vanderwart. In many cases, some of the pictures were slightly different so that we were able to calculate the reliability between the two lists of stimuli.

\section{Method}

Participants. A further sample of 380 schoolchildren (190 boys and 190 girls) attending infant, primary, and secondary schools in Oviedo were recruited. All had normal or corrected-to-normal sight; they had no problems at school, and their native language was Spanish. None of them had participated in the previous study. Their socioeconomic level was average and equal to that of the participants in the previous study. As occurred in the first study, they were put into groups according to 19 age bands, and there were 20 children ( 10 boys and 10 girls) in each band.

Stimuli. All 122 pictures were printed on black and white cards that were of the same size as that used in the previous study.

Procedure. The procedure used was the same as that of the first study. Every child was evaluated in a private room at his or her school. We started with the age band from 56-61 months, and all of the pictures were used. Then, we ascended in age bands with the pictures that had not been named in this band, and we descended in age bands with the ones that were named by $75 \%$ of the children.

\section{Results}

As occurred in the first study, a different level was assigned to the pictures that had been named by $75 \%$ of the children.

\section{Final Battery}

We proceeded to select a single battery with the data from both studies. We found that some stimuli had caused difficulties - in some cases because pictures had not been recognized, in others because low name agreement had been elicited. We decided to remove 14 pictures from the Snodgrass and Vanderwart (1980) set: those of a coat, peanut, lobster, toothbrush, baby carriage, thumb, refrigerator, lips, peach, doll, bread, hair, envelope, and cake. We also removed three pictures from our own battery: those of an olive, sea shell, and circle. Our final item set consisted of 328 pictures - 246 from the Snodgrass and Vanderwart set and 82 new pictures. The data of the objective AoA for each stimulus are accessible from the Psychonomic Archive of Norms, Stimuli, and Data.

In the next section, we report a test on the reliability and validity of our results, the correlation of our AoA values with lexical and semantic variables, and the degree of coincidence with objective AoA values reported in other languages.

Reliability. Since 37 of the pictures that were tested were common to both our study and that of Snodgrass and Vanderwart (1980), we were able to examine the reliability of our AoA values. The correlation between the AoA obtained in both studies for these 37 stimuli was very high $(r=.924, p<.001)$.

Validity. We tested the validity of our objective AoA values by comparing them with values of rated AoA that were reported by Cuetos, Álvarez, González-Nosti, Méot, and Bonin (2006) for 324 items in common with our picture set. The correlation that we found was .558 ( $p<$ $.001)$. A total of 109 items were also common to a survey of objective AoA for picture names reported by Pérez and Navalón (2005). The correlation between their AoA values and ours was .635 $(p<.001)$ for these shared items. This result shows a high validity for this new pictures set.

Correlation with other psycholinguistic variables. A criticism directed at scales of rated AoA has been that they can be determined by variables such as familiarity, word frequency, imageability, word length, or typicality of the stimuli. Individuals tend to consider that they acquired the most frequent and shorter words at an early age, and these words correspond to the most familiar, imaginable, and typical concepts of a category. Some authors (e.g., Pérez \& Navalón, 2005) have found a greater correlation between these variables and rated AoA in comparison with that obtained with objective AoA. We too found that the objective AoA correlates less with the mentioned semantic or lexical variables than does the rated AoA. The differences are very pronounced, especially in relation to 
Table 2

Correlations Between AoA Measures and Other Psycholinguistic Variables

\begin{tabular}{|c|c|c|c|c|c|c|c|c|}
\hline & & Rated AoA & $\begin{array}{c}\text { No. } \\
\text { Phonemes }\end{array}$ & Frequency & $\begin{array}{l}\text { Cumulative } \\
\text { Frequency }\end{array}$ & Familiarity & Imageability & Typicality \\
\hline Objective AoA & $\begin{array}{l}r \\
\text { Two-tailed significance } \\
\text { No. cases }\end{array}$ & $\begin{array}{l}.558 \\
.000 \\
324\end{array}$ & $\begin{array}{l}.129 \\
.019 \\
328\end{array}$ & $\begin{array}{l}-.436 \\
.000 \\
328\end{array}$ & $\begin{array}{l}-.513 \\
.000 \\
311\end{array}$ & $\begin{array}{l}-.368 \\
.000 \\
324\end{array}$ & $\begin{array}{l}-.287 \\
.000 \\
324\end{array}$ & $\begin{array}{l}-.232 \\
.001 \\
202\end{array}$ \\
\hline Rated AoA & $\begin{array}{l}r \\
\text { Two-tailed significance } \\
\text { No. cases }\end{array}$ & & $\begin{array}{l}.267 \\
.000 \\
324\end{array}$ & $\begin{array}{l}-.475 \\
.000 \\
324\end{array}$ & $\begin{array}{l}-.608 \\
.000 \\
307\end{array}$ & $\begin{array}{l}-.538 \\
.000 \\
324\end{array}$ & $\begin{array}{l}-.408 \\
.000 \\
324\end{array}$ & $\begin{array}{l}-.282 \\
.000 \\
200\end{array}$ \\
\hline No. phonemes & $\begin{array}{l}r \\
\text { Two-tailed significance } \\
\text { No. cases }\end{array}$ & & & $\begin{array}{l}-.389 \\
.000 \\
328\end{array}$ & $\begin{array}{l}-.356 \\
.000 \\
311\end{array}$ & $\begin{array}{l}-.194 \\
.000 \\
324\end{array}$ & $\begin{array}{l}-.055 \\
.322 \\
324\end{array}$ & $\begin{array}{l}-.096 \\
.176 \\
202\end{array}$ \\
\hline ACU frequency & $\begin{array}{l}r \\
\text { Two-tailed significance } \\
\text { No. cases }\end{array}$ & & & & $\begin{array}{l}.917 \\
.000 \\
311\end{array}$ & $\begin{array}{l}.467 \\
.000 \\
324\end{array}$ & $\begin{array}{l}.215 \\
.000 \\
324\end{array}$ & $\begin{array}{l}.285 \\
.000 \\
202\end{array}$ \\
\hline Cumulative frequency & $\begin{array}{l}r \\
\text { Two-tailed significance } \\
\text { No. cases }\end{array}$ & & & & & $\begin{array}{l}.497 \\
.000 \\
307\end{array}$ & $\begin{array}{l}.232 \\
.000 \\
307\end{array}$ & $\begin{array}{l}.272 \\
.000 \\
195\end{array}$ \\
\hline Familiarity & $\begin{array}{l}r \\
\text { Two-tailed significance } \\
\text { No. cases }\end{array}$ & & & & & & $\begin{array}{l}.416 \\
.000 \\
324\end{array}$ & $\begin{array}{l}.174 \\
.014 \\
200\end{array}$ \\
\hline Imageability & $\begin{array}{l}r \\
\text { Two-tailed significance } \\
\text { No. cases }\end{array}$ & & & & & & & $\begin{array}{l}.215 \\
.002 \\
200\end{array}$ \\
\hline
\end{tabular}

Note-Objective AoA, own study data; Rated AoA, Cuetos et al (2006); No. Phonemes, word length in phonemes; Frequency, $\log (1+x)$ Alameda and Cuetos (1995) word count; Cumulative Frequency, Alameda and Cuetos (1995) frequencies/2 + Martínez and García (2004a, 2004b) frequencies/2,6, and we applied the formula $\log (1+x)$ to the result; Familiarity, Cuetos et al. (2006); Imageability, Sebastián, Martí, Carreiras, and Cuetos (2000); Typicality, Soto, Sebastián, García, and Del Amo (1994).

familiarity and imageability, which supports the view that subjective estimates of AoA are confounded with familiarity, imageability, and other covariates.

Recently, Zevin and Seidenberg (2002) proposed two new measures of word frequency that better estimate one's lifetime experience of words. They are cumulative frequency and frequency trajectory. These authors argue that frequency estimates computed from counts of word occurrences in adult corpora-values commonly used in psycholinguistics experiments - do not faithfully reflect the frequency with which we experience words, since they do not take into account the frequency of experience during childhood. There are words that we learn earlier-for instance, dragon - but that we see written few times later in life. There are others that we learn later-for instance, process - but that we do use frequently later. In a recent study, we found that it is the cumulative frequency that predicts picture naming latencies better than adult frequency (Cuetos et al., 2006). This is not the case for frequency trajectory, whose effects were not relevant. Consequently, we thought it would be interesting to test the correlation between the objective AoA obtained in this study and the cumulative frequency derived from the data of Alameda and Cuetos's (1995) adult frequency count, together with the data on childhood frequency reported by Martínez and García (2004a, 2004b). The latter analyzed a 2,600,000-word sample that was taken from texts and reading books for children used in the first to sixth grades of primary education, obtaining frequencies for 100,944 different words. In order to calculate cumulative frequencies, we followed the same procedure as that of Cuetos et al. (2006); that is, we obtained the frequencies per million of Alameda and Cuetos (1995) and Martínez and García (2004a, 2004b), then added the frequencies of both counts and applied the formula $\log (1+X)$ to the result. We found a negative significant correlation $(r=-.513$, $p<.001, n=311$ ) between the cumulative frequency for words and our objective AoA estimate for these words that was inferior to the one obtained with rated AoA values, which means that the objective AoA is more independent of word frequency than is rated AoA.

Comparison with other studies that have calculated objective AoA. Since there are many different studies in different languages in which AoA values have been obtained using this procedure, we were able to test the correlation with the values that we obtained for the stimuli that were common across studies. As far as we know, similar studies have been done in Italian (Barbarotto et al., 2005), French (Chalard et al., 2003), English (Funnell, Hughes, \& Woodcock, 2006; Morrison et al., 1997), Spanish (Pérez \& Navalón, 2005), and Icelandic (Pind et al., 2000). The correlations and the number of stimuli common to each study can be seen in Table 3 .

As we can see in this table, the relationship between our values of objective AoA and the values obtained in other investigations is very high and significant in all cases. The correlation of our data (.890) with that of Funnell et al. (2006) is especially high, despite the small number of common stimuli. The correlation is also high (.709) in Barbarotto et al. (2005). We should point out that these authors followed the same procedure that we did: not giving children the first phoneme of the name when they did 
Table 3

Correlations Between Objective AoA Measures in Different Languages

\begin{tabular}{llcccccc}
\hline & & Barbarotto & Chalard & Funnell & Morrison & Pérez & Pind \\
\hline Álvarez \& Cuetos & $r$ & .709 & .524 & .890 & .554 & .635 & .483 \\
& Two-tailed significance & .000 & .000 & .000 & .000 & .000 & .000 \\
& No. Cases & 65 & 188 & 34 & 217 & 109 & 214 \\
Barbarotto et al. (2005) & $r$ & & .701 & .821 & .667 & .448 & .559 \\
& Two-tailed significance & & .000 & .001 & .000 & .005 & .000 \\
& No. cases & & 56 & 21 & 56 & 37 & 55 \\
Chalard et al. (2003) & $r$ & & .142 & .668 & .585 & .587 \\
& Two-tailed significance & & & .471 & .000 & .000 & .000 \\
& No. cases & & 28 & 171 & 88 & 175 \\
Funnell et al. (2006) & $r$ & & & .421 & .834 & -.048 \\
& Two-tailed significance & & & & .023 & .000 & .810 \\
& No. cases & & & & 29 & 16 & 27 \\
Morrison et al. (1997) & $r$ & & & & & .722 & .716 \\
& Two-tailed significance & & & & & .000 & .000 \\
& No. cases & & & & & & \\
Pérez \& Navalón (2005) & $r$ & & & & & .56 \\
& Two-tailed significance & & & & & .000 \\
& No. cases & & & & & 97 \\
\hline
\end{tabular}

Note-Pind, Pind et al. (2000).

not know the depicted object, as has been done in other mentioned studies (Chalard et al., 2003; Morrison et al., 1997; Pérez \& Navalón, 2005; Pind et al., 2000).

\section{DISCUSSION}

The main aim of this study was to provide objective AoA data for a large picture set. Many experiments show that AoA is one of the most important variables for determining naming latencies in healthy individuals, as well as accuracy in aphasic patients or in individuals with neurodegenerative illnesses, and that many of the effects that are traditionally attributed to word frequency are actually due to AoA. This is why it is important to compile objective measurements of AoA for the largest possible number of stimuli, so that experimenters will be able to manipulate and control this variable in future studies. In fact, scales of objective AoA have been appearing in most Western languages: English (Funnell et al., 2006; Morrison et al., 1997), Icelandic (Pind et al., 2000), French (Chalard et al., 2003), Italian (Barbarotto et al., 2005). In Spanish, Pérez and Navalón (2005) data concerning 175 pictures have been published. However, their pictures are not standardized. In this study, we obtained objective AoA data for 246 of the 260 Snodgrass and Vanderwart (1980) picture set, which are widely used in laboratory experiments and clinical studies. Together with these pictures, we also collected data for 82 new pictures with a similar format. Moreover, in this study, we were able to show that objective AoA is less contaminated by variables such as familiarity or word frequency than is rated AoA, making the former a better measure of AoA. The rated AoA has a correlation of -.538 with familiarity and of -.475 with word frequency, whereas the correlation of the objective AoA with familiarity is -.368 and -.436 for word frequency. These results are consistent with arguments that were made by Morrison et al. (1997) some time ago - and more recently by Barbarotto et al. (2005) - that objective data concerning AoA are preferred to subjective measures.

A matter that is being debated at present is whether AoA can be reduced to cumulative frequency - that is, to the word frequency estimated by the sum of the childhood frequency and the adult frequency estimates (Zevin \& Seidenberg, 2002). In this study, we found a correlation of -.513 between objective AoA and cumulative frequency, whereas the correlation between rated AoA and cumulative frequency was greater $(-.608)$. We have recently verified (Cuetos et al., 2006) that AoA predicts naming latencies better than cumulative frequency. All of these factors indicate that AoA is an independent and important variable in lexical semantic studies.

However, the objective AoA that we obtained in this study correlates in a very significant way with the results obtained with the same procedure in other languages, such as English, French, Icelandic, or Italian, which means that the order of word acquisition varies in a similar manner in all these languages.

In sum, we report objective AoA values for a great number of familiar objects. We are sure that these scales will be very useful to psycholinguists in producing laboratory experiments and also for clinicians in the preparation of diagnostic tests.

\section{AUTHOR NOTE}

This research was supported by Grant MCT-03-BSO-00777 from the Spanish government. We are grateful to Ángel González for the first translation into English. Address correspondence to Fernando Cuetos, Facultad de Psicología, Universidad de Oviedo, Plaza Feijoo, s/n 33003 Oviedo, Spain (e-mail: fcuetos@uniovi.es).

\section{REFERENCES}

Alameda, J. R., \& Cuetos, F. (1995). Diccionario de frecuencias de las unidades lingüísticas del castellano. Oviedo, Spain: Servicio de Publicaciones de la Universidad de Oviedo. 
Alario, F.-X., \& FerRand, L. (1999). A set of pictures standardized for French: Norms for name agreement, image agreement, familiarity, visual complexity, image variability, and age of acquisition. Behavior Research Methods, Instruments, \& Computers, 31, 531-552.

Barbarotto, R., Laiacona, M., \& Capitani, E. (2005). Objective versus estimated age of word acquisition: A study on 202 Italian children. Behavior Research Methods, 37, 644-650.

Barca, L., Burani, C., \& ARduino, L. S. (2002). Word naming times and psycholinguistic norms for Italian nouns. Behavior Research Methods, Instruments, \& Computers, 34, 424-434.

BARRY, C., \& GERHAND, S. (2003). Both concreteness and age-ofacquisition affect reading accuracy but only concreteness affects comprehension in a deep dyslexic patient. Brain \& Language, 84, 84-104.

Barry, C., Morrison, C. M., \& Ellis, A. W. (1997). Naming the Snodgrass and Vanderwart pictures: Effects of age of acquisition, frequency, and name agreement. Quarterly Journal of Experimental Psychology, 50A, 560-585.

Bonin, P., Boyer, B., Méot, A., Fayol, M., \& Droit, S. (2004). Psycholinguistic norms for action photographs in French and their relationships with spoken and written latencies. Behavior Research Methods, Instruments, \& Computers, 36, 127-139.

Bonin, P., Chalard, M., Méot, A., \& Fayol, M. (2001). Age-ofacquisition and word frequency in the lexical decision task: Further evidence from the French language. Cahiers de Psychologie Cognitive/Current Psychology of Cognition, 20, 401-443.

Brysbaert, M., Lange, M., \& Van Wijnendaele, I. (2000). The effects of age-of-acquisition and frequency-of-occurrence in visual word recognition: Further evidence from the Dutch language. European Journal of Cognitive Psychology, 12, 65-85.

Carroll, J. B., \& White, M. N. (1973). Word frequency and age of acquisition as determiners of picture-naming latency. Quarterly Journal of Experimental Psychology, 25, 85-95.

Caselli, M. C., \& Casadio, P. (1995). Il Primo Vocabolario del Bambino. Guida all'uso del questionario MacArthur per la valutazione della comunicazione e del linguaggio nei primi anni di vita. Milán: Franco Angeli.

Chalard, M., Bonin, P., Méot, A., Boyer, B., \& Fayol, M. (2003). Objective age-of-acquisition (AoA) norms for a set of 230 object names in French: Relationships with psycholinguistic variables, the English data from Morrison et al. (1997), and naming latencies. European Journal of Cognitive Psychology, 15, 209-245.

Cuetos, F., Aguado, G., Izura, C., \& Ellis, A. W. (2002). Aphasic naming in Spanish: Predictors and errors. Brain \& Language, 82, 344-365.

Cuetos, F., Álvarez, B., González-Nosti, M., Méot, A., \& Bonin, P. (2006). Determinants of lexical access in speech production: Role of word frequency and age of acquisition. Memory \& Cognition, 34, 999-1010.

Cuetos, F., \& Barbón, A. (2006). Word naming in Spanish. European Journal of Cognitive Psychology, 18, 415-436.

Cuetos, F., Ellis, A. W., \& Álvarez, B. (1999). Naming times for the Snodgrass and Vanderwart pictures in Spanish. Behavior Research Methods, Instruments, \& Computers, 31, 650-658.

Cuetos, F., González-Nosti, M., \& Martínez, C. (2005). The picture-naming task in the analysis of cognitive deterioration in Alzheimer's disease. Aphasiology, 19, 545-557.

Cuetos, F., Monsalve, A., Pinto, A., \& Rodríguez-Ferrero, J. (2004). Predictor variables of written picture naming in the deaf. Reading \& Writing: An Interdisciplinary Journal, 17, 227-240.

Dell'Acqua, R., LotTo, L., \& Job, R. (2000). Naming times and standardized norms for the Italian PD/DPSS set of 266 pictures: Direct comparisons with American, English, French, and Spanish published databases. Behavior Research Methods, Instruments, \& Computers, 32, 588-615.

Ellis, A. W., \& Morrison, C. M. (1998). Real age-of-acquisition effects in lexical retrieval. Journal of Experimental Psychology: Learning, Memory, \& Cognition, 24, 515-523.

Fiebach, C. J., Friederici, A. D., Müller, K., Von Cramon, D. Y., \& HeRnÁNDEZ, A. E. (2003). Distinct brain representations for early and late learned words. NeuroImage, 19, 1627-1637.

Forbes-McKay, K. E., Ellis, A. W., Shanks, M. F., \& Venneri, A. (2005). The age of acquisition of words produced in a semantic flu- ency task can reliably differentiate normal from pathological age related cognitive decline. Neuropsychologia, 43, 1625-1632.

Funnell, E., Hughes, D., \& Woodcock, J. (2006). Age of acquisition for naming and knowing: A new hypothesis. Quarterly Journal of Experimental Psychology, 59, 268-295.

Gerhand, S., \& BARRY, C. (1998). Word frequency effects in oral reading are not merely age-of-acquisition effects in disguise. Journal of Experimental Psychology: Learning, Memory, \& Cognition, 24, 267-283.

Gerhand, S., \& Barry, C. (1999). Age of acquisition, word frequency, and the role of phonology in the lexical decision task. Memory \& Cognition, 27, 592-602.

Ghyselinck, M., De Moor, W., \& Brysbaert, M. (2000). Age-ofacquisition ratings on 2816 Dutch four- and five-letter nouns. Psychologica Belgica, 40, 77-98.

Gilhooly, K. J., \& Logie, R. H. (1980a). Age-of-acquisition, imagery, concreteness, familiarity, and ambiguity measures for 1,944 words. Behavior Research Methods \& Instrumentation, 12, 395-427.

Gilhooly, K. J., \& LogIE, R. H. (1980b). Meaning-dependent ratings of imagery, age of acquisition, familiarity, and concreteness for 387 ambiguous words. Behavior Research Methods \& Instrumentation, 12, 428-450.

Hernández, A. E., \& Fiebach, C. J. (2006). The brain bases of reading late learned words: Evidence from functional MRI. Visual Cognition, 13, 1027-1043.

Hirsh, K. W., \& Ellis, A. W. (1994). Age of acquisition and lexical processing in aphasia: A case study. Cognitive Neuropsychology, 11, 435-458.

Holmes, S. J., \& Ellis, A. W. (2006). Age of acquisition and typicality effects in three object processing tasks. Visual Cognition, 13, 884-910.

JoRM, A. F. (1991). The validity of word age-of-acquisition ratings: A longitudinal study of a child's word knowledge. British Journal of Developmental Psychology, 9, 437-444.

Kohnstamm, G. A., Schaerlaekens, A. M., De Vries, A. K., AkKerHUIS, G. W., \& FroonincksX, M. (1981). Nieuwe streefiijst woordenschat. Lisse: Swets and Zeitlinger.

Lambon Ralph, M. A., Graham, K. S., Ellis, A. W., \& Hodges, J. R. (1998). Naming in semantic dementia - what matters? Neuropsychologia, 36, 775-784.

Martínez, J. A., \& García, M. E. (2004a). Diccionario: Frecuencias del castellano escrito en niños de 6 a 12 años. Salamanca: Servicio de Publicaciones de la Universidad Pontificia de Salamanca.

Martínez, J. A., \& García, M. E. (2004b). Inventario silábico del lenguaje escrito dirigido a los niños de primaria. Cognitiva, 16, 43-56.

Monaghan, J., \& Ellis, A. W. (2002). What exactly interacts with spelling-sound consistency in word naming? Journal of Experimental Psychology: Learning, Memory, \& Cognition, 28, 183-206.

Moore, V. M., \& VAlentine, T. (1998). The effect of age of acquisition on speed and accuracy of naming famous faces. Quarterly Journal of Experimental Psychology, 51A, 485-513.

Morrison, C. M., Chappell, T. D., \& Ellis, A. W. (1997). Age of acquisition norms for a large set of object names and their relation to adult estimates and other variables. Quarterly Journal of Experimental Psychology, 50A, 528-559.

Morrison, C. M., \& Ellis, A. W. (1995). Roles of word frequency and age of acquisition in word naming and lexical decision. Journal of Experimental Psychology: Learning, Memory, \& Cognition, 21, 116-133.

Morrison, C. M., Hirsh, K. W., Chappell, T., \& Ellis, A. W. (2002). Age and age of acquisition: An evaluation of the cumulative frequency hypothesis. European Journal of Cognitive Psychology, 14, 435-459.

Nickels, L. A., \& HowARD, D. (1995). Aphasic naming: What matters? Neuropsychologia, 33, 1281-1303.

Pérez, M. A., \& Navalón, C. (2005). Objective-AoA norms for 175 names in Spanish: Relationships with other psycholinguistic variables, estimated AoA, and data from other languages. European Journal of Cognitive Psychology, 17, 179-206.

Pind, J. L., Jónsdóttir, H., Tryggvadóttir, H. B., \& Jónsson, F. (2000). Icelandic norms for the Snodgrass and Vanderwart (1980) pictures: Name and image agreement, familiarity, and age of acquisition. Scandinavian Journal of Psychology, 41, 41-48.

Piñeiro, A., \& Manzano, M. (2000). A lexical database for Spanish- 
speaking children. Behavior Research Methods, Instruments, \& Computers, 32, 616-628.

Postler, J., De Bleser, R., Kauschke, C., Rainders, S., Weiller, C., \& Büchel, C. (2004, September). The neural processing of naming nouns and verbs with special reference to age-of-acquisition. An event-related fMRI study. Paper presented at The Science of Aphasia Annual Meeting 5 [Academy of Aphasia]: Cross Linguistic Aspects of Aphasia, Potsdam, Germany.

Sanfeliu, M. C., \& Fernández, A. (1996). A set of 254 SnodgrassVanderwart pictures standardized for Spanish: Norms for name agreement, image agreement, familiarity, and visual complexity. Behavior Research Methods, Instruments, \& Computers, 28, 537-555.

Sebastián, N., Martí, M. A., Carreiras, M. F., \& Cuetos, F. (2000). LEXESP: Léxico informatizado del español. Barcelona: Edicions Universitat de Barcelona.

SNOdgrass, J. G., \& VANDERWART, M. (1980). A standardized set of 260 pictures: Norms for name agreement, image agreement, familiarity, and visual complexity. Journal of Experimental Psychology, $\mathbf{6}$, 174-215.

Soto, P., Sebastián, M. V., García, E., \& Del Amo, T. (1994). Las categorias y sus normas en castellano. Madrid: Visor Distribuciones.

TAinturier, M. J., Johnson, E., TAMminen, J., \& Thierry, G. (2003). An ERP investigation of age-of-acquisition effects in spoken word recognition. Brain \& Language, 87, 15-16.

VitKovitch, M., \& Tyrrell, L. (1995). Sources of disagreement in object naming. Quarterly Journal of Experimental Psychology, 48A, $822-848$

Weekes, B. S., Chan, A., Kwok, J. S. W., Tan, L. H., \& Jin, Z. (2004). AoA effects on Chinese language processing: An fMRI study. Brain \& Language, 91, 33-34.

Weekes, B. S., Davies, R., Parris, B., \& Robinson, G. (2003). Age of acquisition effects on spelling in surface dysgraphia. Aphasiology, $17,563-584$.

Yamada, J., TaKashima, H., \& YamazaKi, M. (1998). Effect of easeof-acquisition on naming latency for Japanese kanji: A reanalysis of Yamazaki et al.'s (1997) data. Psychological Reports, 83, 991-1002.
Yamazaki, M., Ellis, A. W., Morrison, C. M., \& Lambon Ralph, M. A. (1997). Two age of acquisition effects in the reading of Japanese Kanji. British Journal of Psychology, 88, 407-421.

Zevin, J. D., \& SeIDenberg, M. S. (2002). Age of acquisition effects in word reading and other tasks. Journal of Memory \& Language, 47, 1-29.

\section{ARCHIVED MATERIALS}

The following materials associated with this article may be accessed through the Psychonomic Society's Norms, Stimuli, and Data archive, www.psychonomic.org/archive.

To access these files, search the archive for this article using the journal name (Behavior Research Methods), the first author's name (Alvaraz), and the publication year (2007).

FILE: Alvarez-BRM-2007.zip

DESCRIPTION: The compressed archive file contains eight files:

AlvarezEtAl(2007)Table1.txt, containing age bands

AlvarezEtAl(2007)Table1.xls, containing the above information in excel spreadsheet format

AlvarezEtAl(2007)Table2.txt, containing correlations between AoA measures and other psycholinguistic variables

AlvarezEtAl(2007)Table2.xls, containing the above information in excel spreadsheet format

AlvarezEtAl(2007)Table3.txt, containing correlations between objective AoA measures in different languages

AlvarezEtAl(2007)Table3.xls, containing the above information in excel spreadsheet format

AlvarezEtAl(2007)Table4.txt, containing spanish name, english name, objective AoA

AlvarezEtAl(2007)Table4.xls, containing the above information in excel spreadsheet format

AUTHOR's E-MAIL ADDRESS: fcuetos@uniovi.es

(Manuscript received February 9, 2006; revision accepted for publication March 6, 2006.) 